\title{
Vertical Ridge Augmentation of Atrophic Anterior Mandible with Autogenic Tibia Grafts Compared Allogenic Grafts
}

\author{
Farnoosh Razmara1, Hamid Mahmoodhashemi' ${ }^{1}$, Shohre Zahraei ${ }^{2}$, Ali Mahmoudhashemi ${ }^{*}$ \\ ${ }^{1}$ Department of Oral and Maxillofacial Surgery, Craniomaxillofacial Research Center, Tehran University of Medical Sciences, \\ Tehran, Iran \\ ${ }^{2}$ Department of Pediatric Dentistry, Dental Branch, Islamic Azad University, Tehran, Iran \\ ${ }^{3}$ Dentist, Private Practice, Tehran, Iran \\ Email: *hashali2619@gmail.com
}

How to cite this paper: Razmara, F., Mahmoodhashemi, H., Zahraei, S. and Mahmoudhashemi, A. (2018) Vertical Ridge Augmentation of Atrophic Anterior Mandible with Autogenic Tibia Grafts Compared Allogenic Grafts. International Journal of Clinical Medicine, 9, 580-589.

https://doi.org/10.4236/ijcm.2018.97049

Received: June 12, 2018

Accepted: July 21, 2018

Published: July 24, 2018

Copyright $\odot 2018$ by authors and Scientific Research Publishing Inc. This work is licensed under the Creative Commons Attribution International License (CC BY 4.0).

http://creativecommons.org/licenses/by/4.0/

\begin{abstract}
Aim: Ridge augmentation for the atrophied mandible or for supporting dental implants is, an effective treatment in patients with alveolar defects that preserve bone height for the placement of implants or desirable appearance. Two common substans for bone augmentation are autografts and allografts. However, it is difficult to demonstrate that one surgical procedure offers better outcomes than another. Our study aimed to address and compare changes in ridge augmentation following autograft and allograft bone grafting within a 6-month follow up period. Materials and Methods: In a randomized blinded clinical trial, 18 patients who were candidates for mandible bone grafts were randomly divided into two autograft (tibia graft) $(n=9)$ and allograft $(n=9)$ groups. In the autograft group demineralized frozen dried bone was used. Height of three local points on graft replacement (Right, Middle and Left points) were measured based on the OPG preoperatively and also 3 and 6 months after the grafting. Results: In all patient, the trend of ridge augmentation change was significant within 6 months following grafting; however no difference was observed in height changes between the autograft and allograft procedures. Conclusion: From the clinical point of view, these two procedures appear to have similar efficacies for treating localized mandibular ridge defects. Clinical Significances: Comparison the success rate and increase the anterior of mandibular height between autogenous bone graft and allogeneic bone graft.
\end{abstract}

\section{Keywords}

Ridge, Ridge Augmentation, Autografting, Tibia, Osteotomy 


\section{Introduction}

Numerous advancements regarding the application of new materials in surgery, in order to increase the under prosthesis surface have led to the greater usage of such materials in surgical interventions for ridge height augmentation. Among such materials, hydroxyapatite and allogens are worth mentioning.

Among the most well-known and oldest materials bone grafts (iliac or ribs) can be named [1] [2]. The most common sources for bone grafts are: autogenic bones, allogenic bones, alloplast or xenograft materials. Generally, if the bone height is less than $15 \mathrm{~mm}$ in the anterior segment of the lower jaw, vestibuloplasty is not practical; the ridge height must be initially augmented and then vestibuloplasty can be applied [3].

The weak points of autogenic grafts are the need for surgery in another body part and severe bone loss (especially in the iliac bone) following the grafting procedure. On the other hand, no need for second surgery in the patient and the patient's better comfort can be mentioned as its strong points [3]. In young patients with moderate atrophy of the alveolar ridge, ridge extension with developed vestibular surface of the jaw or vestibuloplasty seems to be a suitable technique. However, in elderly patients with severe alveolar ridge atrophy, ridge augmentation is more suitable [4].

Autogenic grafts on the mandible are most commonly used when severe bone loss has resulted in reduced bone height and width with a great risk of bone fracture. Moreover, this method is used when adequate bone is not available for placing the dental implant in the bone. However, some studies believe that autogenic grafts have more major complications and therefore allogenic grafts are a suitable alternative for autogenic grafts with fewer complications [5]. The majority of complications caused by autogenic or allogenic grafts include infection following grafting or graft rejection. Moreover, $17 \%$ of patients with a residual bone height of $<6 \mathrm{~mm}$ have experienced graft rejection in the first 3 years [6].

The available literature have mainly focused on ridge augmentation in the maxillary bone and few studies have been performed on the adequacy of these materials in bone grafts for height augmentation of the mandible (especially when the tibia as a donor site). Therefore in this study we aimed at investigating the changes in the height of the ridge following autogenic (tibia graft) and allogenic grafts in the anterior segment of the mandible in a 6-month period, so that a more comprehensive evaluation could be given on the quality of the conducted surgeries.

\section{Materials and Methods}

Our study was a randomized blinded clinical trial performed in the Implant Unit of the Dentistry School of Tehran University of Medical Sciences from 2014 to 2016. The sampling method was random sampling using quadruple blocks. The inclusion criteria were systemically healthy patients (ASA l) and who were no 
physical deformities. Height of anterior segment of mandible was between 10 14 millimeter (mean 12 millimeter). All patients signed the consent form.

Before study initiation, an informed consent was obtained from all participants and the need for treatment follow up for 6 months was described to all patients.

After patients' selection, they were randomly divided into two groups; autogenic tibia grafts were used in group A and allogenic grafts were used in group B. The selected cases were 8 males and 10 females with the mean age of 53 yrs.

In both groups osteotomy was performed using segmental sandwich technique [7].

For osteotomy in the anterior segment of the mandible, a mucosal incision was made in the depth of the vestibule from the premolar region to the premolar in opposite region. Following subperiosteal dissection, the bone region was made accessible. Anterior segmental osteotomy in relation to the mental hole was done and then osteotomy with a saw, two vertical and one horizontal incisions, as a U shape, was made (Figure 1). The upper mobile segment was shifted upwards approximately 8 to 10 millimeter and fixed by two miniplate then space between the mobile segment and the anterior basilar of the mandible was filled with an autogenic or allogenic graft and fixed with two miniplates. It was finally incision sutured with a 3 - 0 silk thread (Figure 2).

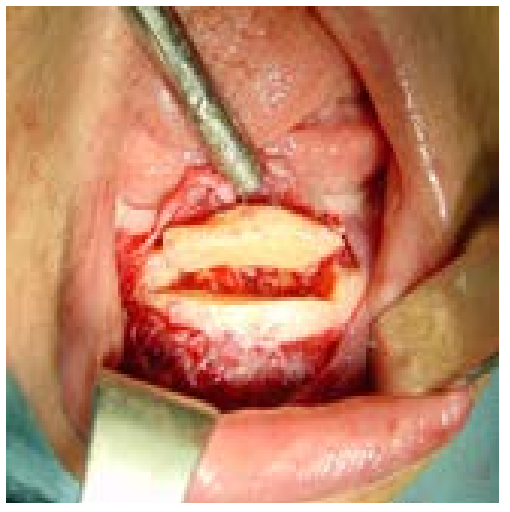

Figure 1. Osteotomy in the anterior segment of the mandible with sandwich technique.

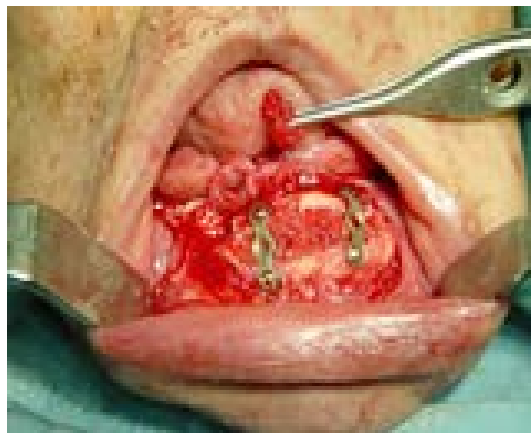

Figure 2. Anterior basilar of the mandible was filled with an autogenic or allogenic graft and fixed with two miniplates. 
In group A, after the tibia bone graft was initially prepared as follows; in the metaphysic region which has cancellous bone, an oblique cut was made. After reaching the tibia region, a trephine drill with $12 \mathrm{~mm}$ diameter was made in the cortical bone of the cavity; some cancellous bone was harvested and skin also sutured. The valve was then fixed in its position and sutured with a $3-0$ absorbable suture [8] (Figure 3).

It is worth mentioning that the level of ridge upward shift was similar in all patients, equal to the height of the plates used. During interpositional osteotomy, it was necessary that the lingual soft tissue connections to the osteotomy segment remained intact, so that the blood flow of the mobile part was not disrupted.

Panoramic radiographic views were taken from all patients before surgery (Figure 4), and immediately after surgery (Figure 5) at the 3 and 6 month follow-up visits. Three months after surgery, the patients returned with a control OPG and underwent miniplates removal surgery. During the removal of screws and plates in all 18 patients, the bone had desirable consistency in the receptor site.

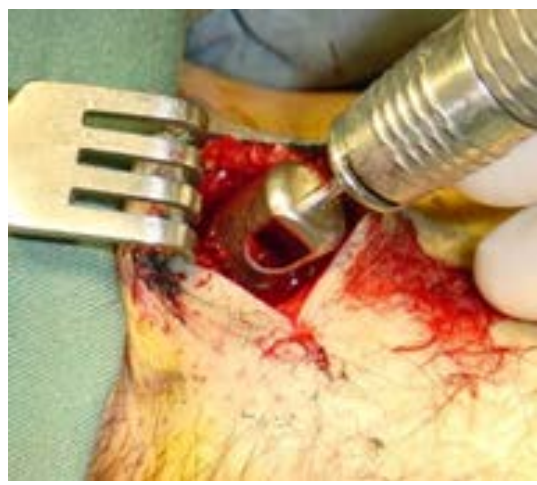

Figure 3. Tibia bone graft with trephine drill.

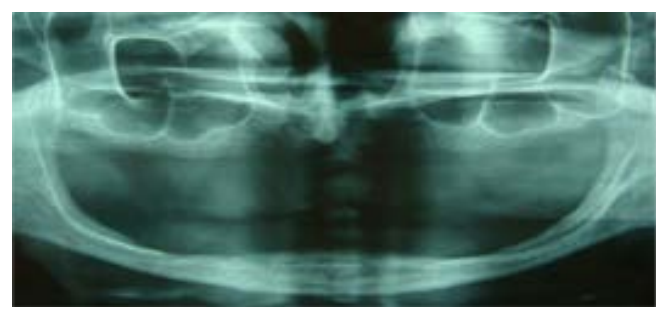

Figure 4. Initial OPG before surgery.

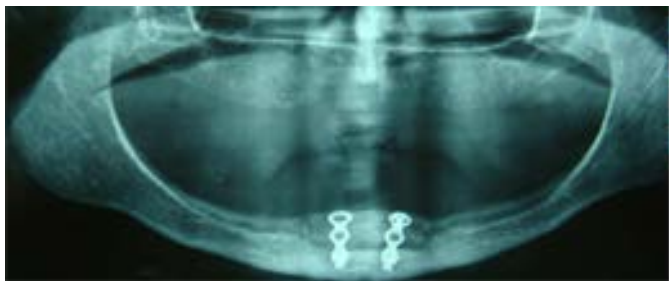

Figure 5. Immediately after surgery. 
After 6 months all OPGs were studied and compared, in each OPG three points in the grafted site were selected (Figure 6). The choice of 3 points was due to having a higher confidence coefficient.

The selected $M$ or middle point is the midline in the OPG and the R and $L$ points are in $10 \mathrm{~mm}$ distance from the midline turning to the right or left. The length of these lines was measured with a caliper.

In the initial OPG of each patient, the distance between each two points was studied and compared with its related points in the 3- and 6-month follow-up OPGs.

\section{Results}

To compare the mean of the study data between the two allograft and autograft materials, the general liner model was used. In the middle point, changes during 6 months in both the allogenous and autogenous methods was statistically significant $(P=0.002)$. However, no significant difference was observed between the two methods regarding changes in ridge height augmentation $(P=0.317)$.

In the selected left point (L), the height of the mandibular ridge, 3 months after the allogenic bone graft had increased from $15.83 \pm 1.89$ to $20.33 \pm 1.53 \mathrm{~mm}$, showing statistical significance (Table 1). Moreover, the height of the ridge 3 months after the autogenous graft increased from $17.33 \pm 0.58$ to $24.33 \pm 0.58$ $\mathrm{mm}$ (Table 2), again indicating a significant difference in comparison to that before grafting. Furthermore, in the left point, regarding the changes in the ridge height during 6 months after grafting, although these changes were statistically significant in both the allogenous and autogenous grafts $(P=0.001)$, yet no meaningful difference was observed between the two methods regarding ridge height augmentation $(P=0.128)$.

In the selected right point $(\mathrm{R})$ the mandibular ridge height three months after the allogenic graft increased from $15.67 \pm 2.08$ to $21.33 \pm 1.04 \mathrm{~mm}$, indicating a significant difference (Table 3 ). An increase from $17.17 \pm 0.76$ to $24.33 \pm 0.58$ $\mathrm{mm}$ was recorded in the ridge height 3 months after the autogenic graft, again being statistically significant. In the R point, during the 6 months after grafting, although the changes in both the allogenic and autogenic methods were statistically significant $(P=0.003)$, yet regarding the inferior ridge height augmentation, no significant difference was achieved between the two methods $(P=0.332)$ (Table 4).

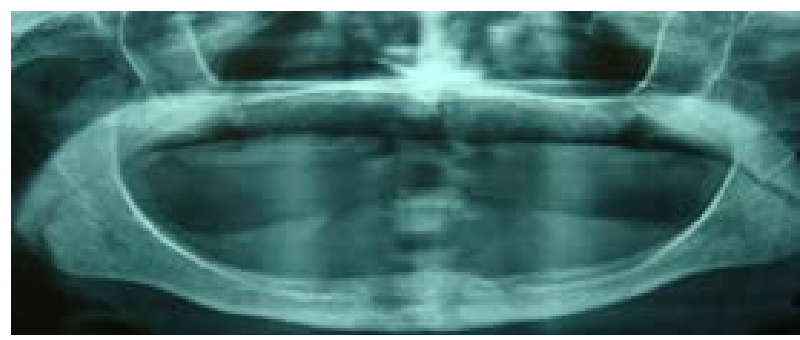

Figure 6. 6 months after surgery. 
Table 1. Mean and 95\% confidence interval, ridge height in the $\mathrm{L}$ point and its value following allogeneic grafting during, 3 and 6 months after surgery.

\begin{tabular}{ccc}
\hline $\begin{array}{c}\text { Average changes in height of ridge height with } \\
\text { allograft }\end{array}$ & $\begin{array}{c}\text { Time interval after } \\
\text { surgery (month) }\end{array}$ & $P$ value \\
\hline $15.83 \pm 1.89$ & Immediately & $P<0.05$ \\
$20.33 \pm 1.53$ & 3 & $P<0.05$ \\
$20.00 \pm 1.00$ & 6 & $P<0.05$ \\
\hline
\end{tabular}

Table 2. Mean and 95\% confidence interval, ridge height in the $\mathrm{L}$ point and its value following autogen grafting during, 3 and 6 months after surgery.

\begin{tabular}{ccc}
\hline $\begin{array}{c}\text { Average changes in height of ridge height with } \\
\text { autogenic grafting }\end{array}$ & $\begin{array}{c}\text { Time interval after } \\
\text { surgery (month) }\end{array}$ & $P$ value \\
\hline $17.33 \pm 0.58$ & Immediately & $P<0.05$ \\
$24.33 \pm 0.58$ & 3 & $P<0.05$ \\
$22.83 \pm 1.26$ & 6 & $P<0.05$ \\
\hline
\end{tabular}

Table3. Mean and 95\% confidence interval, mandibular ridge height in the $\mathrm{R}$ point and its value following allogeneic grafting during, 3 and 6 months after surgery.

\begin{tabular}{ccc}
\hline $\begin{array}{c}\text { Average changes in height of ridge height } \\
\text { with allograft }(\mathrm{mm})\end{array}$ & $\begin{array}{c}\text { Time interval after } \\
\text { surgery (month) }\end{array}$ & $P$ value \\
\hline $15.67 \pm 2.08$ & Immediately & $P<0.05$ \\
$21.33 \pm 1.04$ & 3 & $P<0.05$ \\
$20.50 \pm 0.5$ & 6 & $P<0.05$ \\
\hline
\end{tabular}

Table 4. Mean and 95\% confidence interval, mandibular ridge height in the $\mathrm{R}$ point and its value following autogenic bone grafting during, 3 and 6 months after surgery.

\begin{tabular}{ccc}
\hline $\begin{array}{c}\text { Average changes in height of ridge height with } \\
\text { autogenic graft }(\mathrm{mm})\end{array}$ & $\begin{array}{c}\text { Time interval after } \\
\text { surgery (month) }\end{array}$ & $P$ value \\
\hline $15.83 \pm 1.89$ & Immediately & $P<0.05$ \\
$21.33 \pm 1.53$ & 3 & $P<0.05$ \\
$20.86 \pm 0.76$ & 6 & $P<0.05$ \\
\hline
\end{tabular}

Regarding the $\mathrm{M}$ point, the mandibular ridge height 3 months after the allogenic graft surgery increased from $15.83 \pm 1.89$ to $21.33 \pm 1.53 \mathrm{~mm}$, indicating a significant difference (Table 5). Moreover, the ridge height 3 months after the autogenic graft surgery increased from $18.00 \pm 0.87$ to $24.83 \pm 1.26 \mathrm{~mm}$, demonstrating a statistically significant difference (Table 6).

\section{Discussion}

Various indicators have been introduced in different studies regarding the success rate of bone graft surgeries. Barone et al. mentioned no significant localized infection at the site of transplantation, and graft attachment to the receptor's jaw, the absence of radiolucent surfaces, non-hemorrhage from the site of the 
Table 5. Mean and 95\% confidence interval, ridge height in the $M$ point and its value following allogeneic grafting during, 3 and 6 months after surgery.

\begin{tabular}{ccc}
\hline $\begin{array}{c}\text { Average changes in height of ridge height with } \\
\text { allograft }(\mathrm{mm})\end{array}$ & $\begin{array}{c}\text { Time interval after } \\
\text { surgery (month) }\end{array}$ & $P$ value \\
\hline $15.83 \pm 1.89$ & Immediately & $P<0.05$ \\
$21.33 \pm 1.53$ & 3 & $P<0.05$ \\
$20.86 \pm 0.76$ & 6 & $P<0.05$ \\
\hline
\end{tabular}

Table 6. Mean and 95\% confidence interval, mandibular ridge height in the $\mathrm{M}$ point and its value following autogenic bone grafting during, 3 and 6 months after surgery.

\begin{tabular}{ccc}
\hline $\begin{array}{c}\text { Average changes in height of ridge height with } \\
\text { autogenic graft }(\mathrm{mm})\end{array}$ & $\begin{array}{c}\text { Time interval after } \\
\text { surgery (month) }\end{array}$ & $P$ value \\
\hline $18 \pm 0.87$ & Immediately & $P<0.05$ \\
$24.83 \pm 1.26$ & 3 & $P<0.05$ \\
$24.67 \pm 1.67$ & 6 & $P<0.05$ \\
\hline
\end{tabular}

bone graft and the possibility of successful dental implant placement as the main indicators. They reported a success rate of $96.8 \%$ in their study. Various indicators have been introduced in different studies regarding the success rate of bone graft surgeries [9].

In our study in spite of that no statistics are presented on the possible complications and the outcomes of the two techniques, yet due to no reported cases of infection, no case of radiolucent surface and the surgeon's satisfaction of the experimental surgical outcome, it seems that the success rate was acceptable in both grafting materials. Few studies have been conducted on ridge height augmentation and the bone space resulting from the bone grafts. In the study by Chiapasco et al. the mean increase in the mandibular ramus in autogenic grafts was $4.6 \mathrm{~mm} ; 8$ to $11 \mathrm{~mm}$ increase in the vertical height of calvaria bone grafts was also reported. Regarding the horizontal plane [10], Roccuzzo et al. compared the width increase following autogenic bone grafts of the ramus alone and those of the mandible with the titanium membrane support. Their study showed a mean increase of $4.8 \mathrm{~mm}$ in those with a titanium membrane and $3.6 \mathrm{~mm}$ in the grafts without this membrane, indicating a significant difference [11].

The second finding was that during the 6-month from the grafting, remarkable healing had occurred at the graft site. It seems that considering 6 months as the graft healing time was an acceptable time in our study. Most of similar studies have reported 4 to 6 months as the required graft healing time [9] [10] [11] In the study by Nelson et al., the implant was placed after a 3-month period. The biopsy provided from the recipient's bone and the histological analyses indicated a favorable graft placement for the implant [12]. Some studies have also investigated the results of immediate implant placement after grafting, yielding different outcomes. McCarty et al. inserted two immediate implants in the autogenic graft site in two patients; it was unsuccessful in one case [13]. However, Izuku et 
al. achieved $100 \%$ success by placing an immediate implant in the autogenic graft site [14]. Schliephake et al. concluded that the graft survival rate in women is significantly lower compared to men [15]; due to the small sample size we did not consider the gender predominance in our study. In a systematic review of 13 studies on the ridge augmentation techniques for placing implants, 6 studies had investigated bone augmentation both in the vertical and horizontal planes, 4 had studied the implant placing skills and 3 others had studied grafting for the treatment of non-parallel implants. In general, no difference was observed between these techniques [16].

A systematic review by Aghaloo et al. in 2007 studied the techniques with the highest success rate for preserving the alveolar bone for dental implants and also the highest success rate of graft survival. The studies conducted between 1980 and 2005 were studied. In the maxila sinus, 5128 dental implants with a follow up time of 12 to 102 months were placed. The survival of the autogenic and allogenic grafts was $97 \%$ and $93.3 \%$ respectively; it was $81 \%$ in the alloplast and alloplast xenograft techniques whereas it was $96.6 \%$ in the xenograft technique alone. Regarding ridge height augmentation 2620 implants with a follow up period of 5 to 74 months were studied in which the implant survival was $95.5 \%$, $90.4 \%, 94.7 \%$ and $83.8 \%$, in the aforementioned techniques, respectively [17].

Motamedian and colleagues in a systematic review in 2016, studied the success rate of implants in the autogenic block bone in comparison to the allogenenic ones. The success rate in the autogenic bone grafts was $73.8 \%$ to $100 \%$ and $72.8 \%$ to $100 \%$, respectively. The same figures were $93.3 \%$ to $100 \%$ and $93.7 \%$ to $100 \%$ for allogenic bones. However, due to the need for studies with a longer duration, no definite conclusion was drawn [18].

Metrens et al. performed a study on the short-term loss following vertical bone augmentation by calvaria in comparison to iliac bone. They concluded that calvaria bone has more consistyency in the primary repairing metal in comparison to the iliac bone [19].

Draenert and colleagues conducted a study on the vertical bone augmentation by GBR, local autogenic block, pizosurgery modification techniques and pelvis bone block in which the outcome was the wide popularity of the GBR technique and autogenic bone block with minimum cortex thickness and a large volume of particulated material [20].

In a clinical and histopathological study by Rocchietta et al. regarding vertical bone augmentation with the autogenous block or autogenic particles in combination with GBR, both the mentioned methods following implant and prothesis placement showed a high success rate. However, histopathological study showed a better connection of autogenic bone in relation to allografts [21].

\section{Conclusions}

The present study can be verified from several aspects. Although the two grafting material demonstrated no difference regarding the changes in the ridge 
height, they were very effective in providing the suitable space in the mandible with the aim of removing atrophy or implant placement.

Regarding our findings it can be concluded that both the autogenic and allogenic grafting materials are efficient in ridge height augmentation with the aim of mandibular atrophy rehabilitation or implant placement. No significant difference in terms of the success rate and the recovery time was observed between the two methods.

\section{Conflicts of Interest}

The authors declare no conflicts of interest regarding the publication of this paper.

\section{References}

[1] Misch, C.E. (2008) Contemporary Implant Dentistry. 3rd Edition, Mosby, St. Louis, 839-870.

[2] Perrg, R., Klokevold, P., Sascha, A. and Gouanouic, H. (2002) Advanced Implant Surgery and Bone Grafting Techniques. In: Newman, M.G., Take, H.H. and Carranza, F.A., Eds., Carranza's Clinical Periodontology, 9th Edition, Saunders Co., Philadelphia, 905.

[3] Chen, S.T., Wilson Jr., T.G. and Hammerle, C. (2004) Immediate or Early Placement of Implants Following tooth Extraction: Review of Biologic Basis, Clinical Procedures, and Outcomes. The International Journal of Oral \& Maxillofacial Implants, 19, 12-25.

[4] Perez-Sayans, M., Fernandez-Gonzalez, B., Somoza-Martin, M., Gándara-Rey, J.M. and García-García, A. (2008) Peri-Implant Bone Resorption around Implants Placed in Alveolar Bone Subjected to Distraction Osteogenesis. Journal of Oral and Maxillofacial Surgery, 66, 787-790. https://doi.org/10.1016/j.joms.2007.12.007

[5] Petrungaro, P.S. and Amar, S. (2005) Localized Ridge Augmentation with Allogenic Block Grafts Prior to Implant Placement: Case Reports and Histologic Evaluations. Implant Dentistry, 14, 139-148. https://doi.org/10.1097/01.id.0000163805.98577.ab

[6] Tonetti, M.S. and Hämmerle, C.H. (2008) Advances in Bone Augmentation to Enable Dental Implant Placement: Consensus Report of the Sixth European Workshop on Periodontology. Journal of Clinical Periodontology, 35, 168-172. https://doi.org/10.1111/j.1600-051X.2008.01268.x

[7] Santagata, M., Sgaramella, N., Ferrieri, L., Corvo, G., Tartaro, G. and Amato, S. (2017) Segmental Sandwich Osteotomy and Tunnel Technique for Three-Dimensional Reconstruction of the Jaw Atrophy: A Case Report. International Journal of Implant Dentistry, 3, 14.

[8] Hashemi, H.M. (2008) Oblique Use of a Trephine Bur for the Harvesting of Tibial Bone Grafts. British Journal of Oral and Maxillofacial Surgery, 46, 690-691. https://doi.org/10.1016/j.bjoms.2008.04.003

[9] Barone, A. and Covani, U. (2007) Maxillary Alveolar Ridge Reconstruction with Nonvascularized Autogenous Block Bone: Clinical Results. Journal of Oral and Maxillofacial Surgery, 65, 2039-2046. https://doi.org/10.1016/j.joms.2007.05.017

[10] Chiapasco, M., Romeo, E., Casentini, P. and Rimondini, L. (2004) Alveolar Distraction Osteogenesis vs. Vertical Guided Bone Regeneration for the Correction of Vertically Deficient Edentulous Ridges: A 1 - 3-Year Prospective Study on Humans. 
Clinical Oral Implants Research, 15, 82-95. https://doi.org/10.1111/j.1600-0501.2004.00999.x

[11] Roccuzzo, M., Ramieri, G., Bunino, M. and Berrone, S. (2007) Autogenous Bone Graft Alone or Associated with Titanium Mesh for Vertical Alveolar Ridge Augmentation: A Controlled Clinical Trial. Clinical Oral Implants Research, 18, 286-294. https://doi.org/10.1111/j.1600-0501.2006.01301.x

[12] Nelson, K., Özyuvaci, H., Bilgic, B., Klein, M. and Hildebrand, D. (2006) Histomorphometric Evaluation and Clinical Assessment of Endosseous Implants in Iliac Bone Grafts with Shortened Healing Periods. International Journal of Oral \& Maxillofacial Implants, 21, 392-398.

[13] McCarthy, C., Patel, R.R., Wragg, P.F. and Brook, I.M. (2003) Dental Implants and Onlay Bone Grafts in the Anterior Maxilla: Analysis of Clinical Outcome. The International Journal of Oral \& Maxillofacial Implants, 18, 238-241.

[14] Iizuka, T., Smolka, W., Hallermann, W. and Mericske-Stern, R. (2004) Extensive Augmentation of the Alveolar Ridge Using Autogenous Calvarial Split Bone Grafts for Dental Rehabilitation. Clinical Oral Implants Research, 15, 607-615. https://doi.org/10.1111/j.1600-0501.2004.01043.x

[15] Schliephake, H., Neukam, F.W. and Wichmann, M. (1997) Survival Analysis of Endosseous Implants in Bone Grafts Used for the Treatment of Severe Alveolar Ridge Atrophy. Journal of Oral and Maxillofacial Surgery, 55, 1227-1233. https://doi.org/10.1111/j.1600-0501.2004.01043.x

[16] Clementini, M., Morlupi, A., Canullo, L., Agrestini, C. and Barlattani, A. (2012) Success Rate of Implants Inserted in Horizontal and Vertical Guided Bone Regenerated Areas: A Systemic Review. International Journal of Oral and Maxillofacial Surgery, 41, 847-852. https://doi.org/10.1016/j.ijom.2012.03.016

[17] Aghaloo, T.L. and Moy, P.K. (2007) Which Hard Tissue Augmentation Techniques Are the Most Successful in Furnishing Bony Support for Implant Placement? The International Journal of Oral \& Maxillofacial Implants, 22, 49-70.

[18] Motamedian, S.R., Khojasteh, M. and Khojasteh, A. (2016) Success Rate of Implants Placed in Autogenous Bone Blocks versus Allogenic Bone Blocks: A Systemic Literature Review. Annals of Maxillofacial Surgery, 6, 78-90. https://doi.org/10.4103/2231-0746.186143

[19] Mertens, C., Decker, C., Seeberger, R., Hoffmann, J., Sander, A. and Freier, K. (2013) Early Resorbtion after Vertical Bone Augmentation-A Comparison of Calvarial and Iliac Graft. Clinical Oral Implants Research, 24, 820-825. https://doi.org/10.1111/j.1600-0501.2012.02463.x

[20] Draenert, F.G., Huetzen, D., Neff, A. and Mueller, W.E.G. (2014) Vertical Bone Augmentation Procedures: Basics and Techniques in Dental Implantology. Journal of Biomedical Materials Research Part A, 102, 1605-1613. https://doi.org/10.1002/jbm.a.34812

[21] Rocchietta, I., Simion, M., Hoffmann, M., Trisciuoglio, D., Benigni, M. and Dahlin, C. (2016) Vertical Bone Augmentation with an Autogenous Block or Particles in Combination with Guided Bone Regeneration: A Clinical and Histological Preliminary Study in Humans. Clinical Implant Dentistry and Related Research, 18, 19-29. https://doi.org/10.1111/cid.12267 